\title{
Optimization of Growth medium for Efficient Cultivation of Lactobacillus salivarius i 24 using Response Surface Method
}

\author{
Lim, C.H., ${ }^{1}$ Rahim, R.A., ${ }^{2}$ Ho, Y.W. ${ }^{3}$ and Arbakariya, B.A. ${ }^{1,3, *}$ \\ ${ }^{1}$ Department of Bioprocess Technology, Faculty of Biotechnology and Biomolecular Sciences, Universiti Putra Malaysia, \\ 43400 UPM Serdang, Selangor, Malaysia. \\ ${ }^{2}$ Department of Cell and Molecular Biology, Faculty of Biotechnology and Biomolecular Sciences, Universiti Putra \\ Malaysia, 43400 UPM Serdang, Selangor, Malaysia. \\ ${ }^{3}$ Laboratory of Industrial Biotechnology, Institute of Bioscience, Universiti Putra Malaysia, 43400 UPM Serdang, \\ Selangor, Malaysia. \\ E-mail: arbarif@biotech.upm.edu.my
}

\begin{abstract}
Production of Lactobacillus salivarius i 24 , a probiotic strain for chicken, was studied in batch fermentation using $500 \mathrm{~mL}$ Erlenmeyer flask. Response surface method (RSM) was used to optimize the medium for efficient cultivation of the bacterium. The factors investigated were yeast extract, glucose and initial culture $\mathrm{pH}$. A polynomial regression model with cubic and quartic terms was used for the analysis of the experimental data. Estimated optimal conditions of the factors for growth of $L$. salivarius i 24 were; $3.32 \%(\mathrm{w} / \mathrm{v})$ glucose, $4.31 \%(\mathrm{w} / \mathrm{v})$ yeast extract and initial culture $\mathrm{pH}$ of 6.10 .
\end{abstract}

Keywords: Lactobacillus salivarius, optimization, response surface method, probiotic for chicken.

\section{INTRODUCTION}

The fermentation conditions, such as temperature, $\mathrm{pH}$, medium composition, dissolved oxygen tension (DOT) and types of neutralizer greatly influence the growth of lactobacilli (Gilliland, 1985). The factors to be considered in the formulation of growth medium are costs, ability to produce a large number of cells and must be able to ease the harvesting method.

The "change one factor at a time" method is widely used as a conventional technique for multifactor experimental design. This method, which involves changing one independent variable while maintaining all others at a fixed level, is extremely time consuming and expensive when a large number of variables are evaluated. This method may also lead to unreliable results and wrong conclusions. It is inferior to the factorial design method (Logothetis and Wynn, 1989). Response surface methodology (RSM), which includes factorial design and regression analysis, is more suitable to be used with multifactor experiments. Hence, it can be employed to overcome the above difficulty. RSM is a collection of statistical techniques for designing experiments, building models, evaluating the effect of factors, and searching optimum conditions of factors for desirable responses (Montgomery, 1991). The relationships between a response and several related factors are quantitative which cover the tested experimental range and include the interactions. The models obtained can be used to calculate any or all combinations of variables, and their effects within the test range.

*Corresponding author
Optimization through factorial design and response surface analysis is a common practice in fermentation technology. This technique has been applied for the optimization of culture conditions (Rao et al., 1993; Cordenunsi et al., 1985) and medium composition (Sen, 1997) for various fermentation processes. From our previous work, growth medium for efficient cultivation of Lactobacillus salivarius i 24 , a potential probiotic for chicken, has been formulated (Lim, 2006). Among the difference carbon and nitrogen sources tested, growth of this bacterium was enhanced by glucose and yeast extract. Growth was also greatly influence by the culture $\mathrm{pH}$. Optimization of the medium and culture conditions shall be carried out to further enhance the cultivation performance of $L$. salivarius prior to large scale production for commercialization.

The main objective of this study was to find the optimum conditions of important factors that affected the cultivation performance of $L$. salivarius i 24 using RSM. The response investigated was the growth of $L$. salivarius i 24 represented by $\log _{10} \mathrm{CFU} / \mathrm{mL}$ and the factors were glucose, yeast extract and $\mathrm{pH}$.

\section{MATERIALS AND METHODS}

\section{Microorganism}

The bacterium, Lactobacillus salivarius i 24 , isolated from chicken intestine (Jin et al., 1996), was used throughout the study. It was kindly provided by the Digestive Microbiology Unit, Laboratory of Industrial Biotechnology, Institute of Bioscience, Universiti Putra Malaysia, Serdang. This bacterium has very good probiotic effect to 
chicken, such as improved resistance to infectious disease, increased growth rate and improved feed digestion (Jin et al., 1996; Jin et al., 1997). The strain was inoculated into De-Man, Rogosa and Sharpe (MRS) broth and incubated at $37^{\circ} \mathrm{C}$ for $24 \mathrm{~h}$. The bacterial cells were then harvested by centrifugation at $12,857 \times \mathrm{g}$ for 5 $\min$ at $4{ }^{\circ} \mathrm{C}$. The bacterial pellets were resuspended in $15 \%(\mathrm{v} / \mathrm{v})$ glycerol and stored at $-80{ }^{\circ} \mathrm{C}$ until used in inoculum preparation.

\section{Medium Composition}

The basal fermentation medium for good growth of $L$. salivarius as reported in our previous work (Lim, 2007) was used in this study. This medium consisted of $(\mathrm{g} / \mathrm{L})$ : $\mathrm{K}_{2} \mathrm{HPO}_{4}, 2$; $\mathrm{MgSO}_{4}, 0.02$; Tween $80,1 \mathrm{~mL} / \mathrm{L}$. The amounts of yeast extract and glucose added were varied according to the requirement of each experiment. The initial $\mathrm{pH}$ of each medium was adjusted to the required value either with $5 \mathrm{M} \mathrm{NaOH}$ or $5 \mathrm{M} \mathrm{HCl}$. The respective fermentation media of yeast extract, glucose and $\mathrm{pH}$ are shown in Table 1.

\section{Cultivation Experiments}

For inoculum preparation, stock culture of $L$. salivarius I 24 was sub-cultured in a $250 \mathrm{~mL}$ Erlenmeyer flask containing $50 \mathrm{~mL}$ of MRS broth. The flask was incubated at $37^{\circ} \mathrm{C}$ for $16-18 \mathrm{~h}$ to obtain the final cell concentration of approximately $10^{7} \mathrm{CFU} / \mathrm{mL}$. For rapid estimation of cell concentration, correlation between $\mathrm{CFU} / \mathrm{mL}$ with cell turbidity measured using a spectrophotometer (Spectronic 20 Genesys) at $620 \mathrm{~nm}$ was used (data not shown).

The cultivation experiments were performed using $100-\mathrm{mL}$ volumes of culture medium in $500 \mathrm{~mL}$ Erlenmeyer flasks. The culture medium was inoculated with $4 \%(\mathrm{v} / \mathrm{v})$ of inoculum, which was prepared as described above. The flasks were incubated at $37^{\circ} \mathrm{C}$ in an orbital shaker at $100 \mathrm{rpm}$, to provide good mixing, for 14 to $18 \mathrm{~h}$. Lactobacilli are not obligate anaerobes and could survive under minimal exposure to oxygen. Flask agitated at low speeds provided better growth conditions to Lactobacillus spp as compared to static flask, due to improvement in mixing (Liew, 2005). During the cultivation, $\mathrm{pH}$ was not controlled but the initial $\mathrm{pH}$ was set at different values ranging from 5 to 7 (Table 1). During cultivation, samples were withdrawn at $2 \mathrm{~h}$ intervals for analysis.

\section{Analytical Techniques}

The number of viable cells was determined as colony forming units (CFU) viability counts, serial decimal dilutions of each sample $\left(10^{-5}\right.$ to $\left.10^{-9}\right)$ were prepared and plated in triplicates onto MRS agar plates. The plates were incubated at $37^{\circ} \mathrm{C}$ for $48 \mathrm{~h}$, after which the colonies on the plate were counted. Each colony was derived from a single viable cell or a colony forming unit (CFU).
Table 1: Actual factor level corresponding to coded factor levels

\begin{tabular}{lllllll}
\hline Factor & \multirow{2}{*}{$\begin{array}{l}\text { Symb } \\
\text { ol }\end{array}$} & \multicolumn{5}{c}{ Actual factor levels at coded factor } \\
& & \multicolumn{5}{c}{ level of } \\
\cline { 2 - 7 } & $\mathrm{X}_{1}$ & 1.5 & 2.3 & 3.5 & 4.7 & 5.5 \\
\hline $\begin{array}{l}\text { Glucose } \\
(\%)\end{array}$ & & & 2 & 3.5 & 5 & 6 \\
$\begin{array}{l}\text { Yeast } \\
\begin{array}{l}\text { Extract } \\
(\%)\end{array}\end{array}$ & $\mathrm{X}_{2}$ & 1 & 2 & & & \\
$\mathrm{pH}$ & $\mathrm{X}_{3}$ & 5 & 5.4 & 6 & 6.6 & 7 \\
\hline
\end{tabular}

\section{Experimental Design using RSM}

A central composite design in two blocks was used to allocate treatment combinations in this experiment (Table 2). The blocks were used to determine the effect of uncontrolled environment to the result of the experiments, in this case the effect of the difference days in conducting the experiment (Liew et al., 2005). The experiment was conducted for two days. The first block, representing the first day of the experiment, contains the factorial runs and 3 centre runs. The second block, representing the second day of the experiment, contains 1 factorial run, 6 axial runs and 3 centre runs.

In this experiment, the growth of $L$. salivarius i 24 as measured by $\log _{10} \mathrm{CFU} / \mathrm{mL}$, was studied under the influence of 3 main factors; glucose, yeast extract and $\mathrm{pH}$. This design was based on the results of the preliminary study on the formulation of medium suitable to support good growth of $L$. salivarius i 24 (Lim, 2006). Growth of $L$. salivarius i 24 was enhanced when glucose and yeast extract was used as carbon and nitrogen source, respectively. Growth of this bacterium was also increased with increasing glucose and yeast extract up to $5 \%$ and $4.5 \%$, respectively. It is well known that growth of Lactobacillus spp is greatly influence by the culture $\mathrm{pH}$ (Schepers et al., 2002; Liew, 2004). The central composite design was aimed at finding the optimum combination of these three factors (glucose, yeast extract and $\mathrm{pH}$ ) on final cell concentration could be attained and also the productivity, which related to the fermentation time.

To set up a statistical model, let $Y$ denotes $\log _{10} \mathrm{CFU} / \mathrm{mL}$ and determined code factor levels as follows: $X_{1}=$ (glucose-3.5)/1.2, $\quad X_{2}=$ (yeast extract$3.5) / 1.5$ and $X_{3}=(p H-6) / 0.6$. Table 1 contains actual factor levels corresponding to coded factor levels. For each factor, a centre point level was set to zero as coded level. Using this design, we can fit a second or higher order polynomial regression model to the data. Treatment combinations and observed responses are presented in Table 2. 
Table 2: Treatment combinations and responses

\begin{tabular}{|c|c|c|c|c|c|}
\hline \multirow[b]{2}{*}{ Run } & \multirow[b]{2}{*}{ Block $^{a}$} & \multicolumn{3}{|c|}{ Coded variable level } & \multirow{2}{*}{$\begin{array}{c}\text { Response }^{b} \\
Y\end{array}$} \\
\hline & & $\mathbf{X 1}$ & $\mathrm{X} 2$ & X3 & \\
\hline 1 & -1 & -1 & -1 & -1 & 9.115 \\
\hline 2 & -1 & -1 & -1 & 1 & 9.319 \\
\hline 3 & -1 & -1 & 1 & -1 & 9.469 \\
\hline 4 & -1 & -1 & 1 & 1 & 9.264 \\
\hline 5 & -1 & 1 & -1 & -1 & 9.053 \\
\hline 6 & -1 & 1 & -1 & 1 & 9.271 \\
\hline 7 & -1 & 1 & 1 & -1 & 9.369 \\
\hline 8 & -1 & 0 & 0 & 0 & 9.402 \\
\hline 9 & -1 & 0 & 0 & 0 & 9.472 \\
\hline 10 & -1 & 0 & 0 & 0 & 9.415 \\
\hline 11 & 1 & 1 & 1 & 1 & 9.447 \\
\hline 12 & 1 & 1.682 & 0 & 0 & 9.301 \\
\hline 13 & 1 & $1 . \overline{682}$ & 0 & 0 & 9.351 \\
\hline 14 & 1 & 0 & 1.682 & 0 & 9.444 \\
\hline 15 & 1 & 0 & $1 . \overline{682}$ & 0 & 8.738 \\
\hline 16 & 1 & 0 & 0 & 1.682 & 9.344 \\
\hline 17 & 1 & 0 & 0 & $\overline{-}$ & 9.129 \\
\hline 18 & 1 & 0 & 0 & 0 & 9.379 \\
\hline 19 & 1 & 0 & 0 & 0 & 9.347 \\
\hline 20 & 1 & 0 & 0 & 0 & 9.412 \\
\hline
\end{tabular}

\section{Statistical Analysis}

Statistical analysis was aimed at determining the fitness of the equations in predicting the number of viable cells in the terms of $\log _{10}$ as response of the independent variables. The data were analysed by the Statistical Analysis System (SAS). SAS/STAT procedures were used for regression analysis (SAS Institute Inc., 1990a). Our regression model permitted evaluation of the effect of linear, interaction, quadratic, cubic and quartic terms of the independent variables (glucose, yeast extract and $\mathrm{pH}$ ) on the response. The $\alpha$-level at which every term in the selected model should be significant was set as 0.05 . Optimum conditions were found through SAS data-step programming. Response surface plots were generated by SAS/GRAPH (SAS Institute Inc., 1990b).

\section{RESULTS AND DISCUSSION}

\section{Development of a Regression Model}

Firstly, the second-order polynomial regression model containing three linear, three quadratic and three interaction terms plus one block term was employed by using the RSREG procedure of SAS/STAT. Table 3 shows that the second-order model was significant and that the $R^{2}=0.9030$. However, the lack of fit was significant $(P=0.0286<0.05)$. This result suggests that the second-order model did not accurately represent data in the experimental region. Therefore, higher order might have to be included in the regression model. Cubic and quartic terms can be included in the model using a model selection procedure in order to eliminate the lack of fit (Oh et al., 1995; Schepers et al., 2002). Since each factor has five levels, up to quartic terms could be included into the model (Box and Draper, 1982).

Variable selection techniques were used to find a better model. Among the variable selection techniques available in the REG procedure of SAS, the smallest Mallows' $C p$ selection and maximum $R^{2}$ improvement techniques were used. Besides that, the sparcity of effect principle was also taken into account when trying to select good predictors from the following candidates for model terms:

$$
\begin{gathered}
\text { Block, } \\
\mathrm{X}_{1}, \mathrm{X}_{2}, \mathrm{X}_{3} \\
\mathrm{X}_{1} \mathrm{X}_{2}, \mathrm{X}_{1} \mathrm{X}_{3}, \mathrm{X}_{2} \mathrm{X}_{3} \\
\mathrm{X}_{1}{ }^{2}, \mathrm{X}_{2}{ }^{2}, \mathrm{X}_{3}{ }^{2} \\
\mathrm{X}_{1}{ }^{3}, \mathrm{X}_{2}{ }^{3}, \mathrm{X}_{3}{ }^{3} \\
\mathrm{X}_{1}^{4}, \mathrm{X}_{2}{ }^{4}, \mathrm{X}_{3}{ }^{4}
\end{gathered}
$$

Table 3: Analysis of variance for evaluation of the second-order model ${ }^{a}$

\begin{tabular}{cccccc}
\hline $\begin{array}{c}\text { Source } \\
\text { of } \\
\text { variation }\end{array}$ & $\begin{array}{c}\text { No of } \\
\text { degrees } \\
\text { of } \\
\text { freedom }\end{array}$ & $\begin{array}{c}\text { Sum of } \\
\text { square }\end{array}$ & $\begin{array}{c}\text { Mean } \\
\text { square }\end{array}$ & $\begin{array}{c}\mathbf{F} \\
\text { value }\end{array}$ & $\begin{array}{c}\mathbf{P} \\
\text { value }\end{array}$ \\
\hline $\begin{array}{c}\text { Model } \\
\text { Residual }\end{array}$ & 9 & 0.539235 & 0.053924 & 8.381 & 0.0019 \\
$\begin{array}{c}\text { Lack of } \\
\text { fit }\end{array}$ & 5 & 0.053024 & 0.0010605 & 8.683 & 0.0286 \\
$\begin{array}{c}\text { Pure } \\
\text { error }\end{array}$ & 4 & 0.004885 & 0.001221 & & \\
Total & 19 & 0.597145 & & & \\
\hline${ }^{a} R^{2}=0.9030$, Coefficient of variance $=0.8623$ & & \\
\hline
\end{tabular}

The same 9-variables model was identified by application of all three of the variable selection methods mentioned above. The functional form of this model is as follows:

$$
\begin{gathered}
Y=b_{0}+b_{1} X_{1}+b_{2} X_{2}+b_{3} X_{3}+b_{11} X_{1}^{2}+b_{22} X_{2}^{2}+b_{222} X_{2}^{3}+ \\
b_{2222} X_{2}^{4}+b_{33} X_{3}^{2}+b_{23} X_{2} X_{3} \\
\text { [equation 1] }
\end{gathered}
$$

Tables 4 and 5 show how the above model was fitted to the data. The fourth-order subset model in Table 5, which was to be used as the response surface model for subsequent analysis, was superior to the second-orderfull model in Table 3; it had a larger $R^{2}(0.9393>0.9030)$ and smaller coefficient of variation $(0.64746<0.8623)$ and smaller number of variables $(9<10)$ and all the regression coefficients were lower than $5 \%$, indicating 
that they were significant. The larger the $R^{2}$, the more accurately the values of the response can be predicted by the model. Furthermore, the lack of fit was insignificant $(P=0.0903)$. However, $X_{1}, X_{2}$ and $X_{2}^{2}$ with $p$
$>0.05$ were forced into the final equation due to the fact that its corresponding higher-order terms were chosen for inclusion. The intercept $b_{0}$ is the estimated response at the center point $\left(X_{1}, X_{2}, X_{3}\right)=(0,0,0)$.

Table 4: Analysis of variance in the regression model selected through variable selection ${ }^{a}$

\begin{tabular}{ccccc}
\hline $\begin{array}{c}\text { Source of } \\
\text { variation }\end{array}$ & $\begin{array}{c}\text { No of degrees } \\
\text { of freedom }\end{array}$ & Sum of square & Mean square & F value \\
\hline $\begin{array}{c}\text { Model } \\
\text { Residual }\end{array}$ & 9 & 0.56087 & 0.06232 & 17.181 \\
Lack of fit & 10 & 0.03627 & 0.00363 & 0.0001 \\
Pure error & 6 & 0.031385 & 0.005231 & 0.0903 \\
Total & 4 & 0.004885 & 0.001221 & \\
\end{tabular}

${ }^{a} R^{2}=0.9393$, Coefficient of variance $=0.64746$

Table 5: Coefficient estimates in the regression model selected through variable selection

\begin{tabular}{ccccc}
\hline Variable & $\begin{array}{c}\text { Coefficient } \\
\text { estimate }\end{array}$ & $\begin{array}{c}\text { Standard } \\
\text { error }\end{array}$ & t value & $\begin{array}{c}\mathbf{P} \\
\text { value }\end{array}$ \\
\hline Intercept & 9.404500 & 0.02458758 & 382.490 & 0.0001 \\
$\mathrm{X}_{1}$ & -0.008134 & 0.01629649 & -0.499 & 0.6285 \\
$\mathrm{X}_{2}$ & 0.038193 & 0.03572549 & 1.069 & 0.3102 \\
$\mathrm{X}_{3}$ & 0.048076 & 0.01629649 & 2.950 & 0.0145 \\
$\mathrm{X}_{1}{ }^{2}$ & -0.027747 & 0.01738176 & -1.596 & 0.1415 \\
$\mathrm{X}_{2}{ }^{2}$ & 0.015734 & 0.04772295 & 0.330 & 0.7484 \\
$\mathrm{X}_{2}{ }^{3}$ & 0.060682 & 0.01808672 & 3.355 & 0.0073 \\
$\mathrm{X}_{2}{ }^{4}$ & -0.044730 & 0.01842177 & -2.428 & 0.0356 \\
$\mathrm{X}_{3}{ }^{2}$ & -0.059382 & 0.01738176 & -3.416 & 0.0066 \\
$\mathrm{X}_{2} \mathrm{X}_{3}$ & -0.068625 & 0.0219347 & -3.223 & 0.0091 \\
\hline
\end{tabular}

Note: The variables which gave $P$ values higher than 0.5 , which are not significant, are not presented in this table.

\section{Determining the Optimum Point of the Factors}

This response surface model can be written as:

$$
\begin{gathered}
Y=b_{0}+f_{1}\left(X_{1}\right)+f_{23}\left(X_{2}, X_{3}\right) \\
\text { equation 2] } \\
\text { Where } \\
f_{1}\left(X_{1}\right)=b_{1} X_{1}+b_{11} X_{1}^{2} \\
f_{23}\left(X_{2}, X_{3}\right)=b_{2} X_{2}+b_{22} X_{2}^{2}+b_{222} X_{2}^{3}+b_{2222} X_{2}^{4}+b_{3} X_{3}+ \\
b_{33} X_{3}^{2} b_{23} X_{2} X_{3}
\end{gathered}
$$

The optimum value of $X_{1}$ that maximized $f_{1}\left(X_{1}\right)$ was found through differentiation. $X_{2}$ and $X_{3}$ that maximized $f_{23}\left(X_{2}, X_{3}\right)$ were maximized through calculation and sorting of $f_{23}\left(X_{2}, X_{3}\right)$ values on a grid of points for $X_{2}$ and $X_{3}$. The search was done with computer programs written in SAS (data not shown).

The optimum point obtained through this study was $\left(X_{1}, X_{2}, X_{3}\right)=(-0.147,0.54,0.15)$. By encoding the coded levels back to the original levels, the following results were obtained: glucose $=33.24 \mathrm{~g} / \mathrm{L}$, yeast extract $=$ $43.1 \mathrm{~g} / \mathrm{L}$ and $\mathrm{pH}=6.1$. The estimated maximum response corresponding to the optimum factor levels was 9.440 $\log _{10} \mathrm{CFU} / \mathrm{mL}$, which was slightly higher than the center factor levels, $9.404 \log _{10} \mathrm{CFU} / \mathrm{mL}$. This was a slight improvement claimed by the regression model. A validation experiment would ascertain whether there was a real improvement.

\section{Assessment of Factor Effects with the Partial-effects Plot}

The partial-effect functions and plots were used to determine the effect of each factor graphically. The partial-effect function of a certain factor is a function that describes how the response moves as the level of that factor changes when the other factors are fixed at their optimum levels (Liew, 2005). Let $Y=f\left(X_{1}, X_{2}, X_{3}\right)$ denote the response surface model described in Tables 5.4 and 5.5 and $\left(\mathrm{X}_{1}{ }^{*}, \mathrm{X}_{2}{ }^{*}, \mathrm{X}_{3}{ }^{*}\right)$ denote the optimum points of the factors which are, $(-0.147,0.54,0.15)$, in this study. Hence, the partial-effect function of $X_{1}$ is defined as

$$
\begin{gathered}
Y\left(X_{1}\right)=f\left(X_{1}, X_{2}{ }^{*}, X_{3}{ }^{*}\right) \\
\text { [equation 3] }
\end{gathered}
$$

Similarly, the partial-effect functions of $\mathrm{X}_{2}$ and $\mathrm{X}_{3}$ are defined as:

$$
\begin{gathered}
Y\left(X_{2}\right)=f\left(X_{1}{ }^{*}, X_{2}, X_{3}{ }^{*}\right) \\
\text { [equation 4] } \\
Y\left(X_{3}\right)=f\left(X_{1}{ }^{*}, X_{2}{ }^{*}, X_{3}\right)
\end{gathered}
$$$$
\text { [equation 5] }
$$ 
The partial-effect curve was drawn with the vertical axis representing $Y\left(X_{j}\right)$ and the horizontal axis representing $X_{j}$. By overlaying all partial-effect curves, we would get the partial-effects plot. In the partial-effects plot, since all $X_{j}$ have common coded-factor levels, we let the horizontal axis represent the common coded-factor level. Figure 1 is the partial-effects plot of the factors investigated. The partial-effect curve for $\mathrm{pH}\left(\mathrm{X}_{3}\right)$ was the most prominent, as indicated by the changes within the -1 and +1 region of the coded level. This observation is also supported by the data of $P$ values presented in Table 5, which shows that the quadratic effect of glucose (X1) and yeast extract $\left(X_{2}\right)$ are higher than 0.05 , indicating that the effect was insignificant. However, the $\mathrm{P}$ value of $\mathrm{pH}$ effect $\left(X_{3}\right)$ is very much lower than 0.05 , suggesting that the effect was very significant. In addition the coefficient estimate for $\mathrm{X}_{3}^{2}(0.06)$ was higher than for $\mathrm{X}_{1}{ }^{2}(0.03)$ and for $\mathrm{X}_{2}{ }^{2}$ (0.02). As shown in Figure 1, the partial effect of yeast extract was higher than the partial effect of glucose, suggesting that yeast extract has more influence on growth of $L$. salivarius i 24 than glucose. Aeschlimann (1989) and Schepers et al. (2002) claimed that the growth of $L$. helveticus was limited by nitrogen substrate in whey permeate, due to low content of total nitrogen as compared to lactose. The partial-response curves of glucose and $\mathrm{pH}$ also showed a pronounced change; the estimated response increased rapidly until the coded levels of glucose and $\mathrm{pH}$ reached 0 and then declined gradually after the glucose and $\mathrm{pH}$ percentages became higher than their coded level of 0 . This happened while the other factors were fixed at their optimum levels.

$\log _{10} \mathrm{CFU} / \mathrm{mL}$

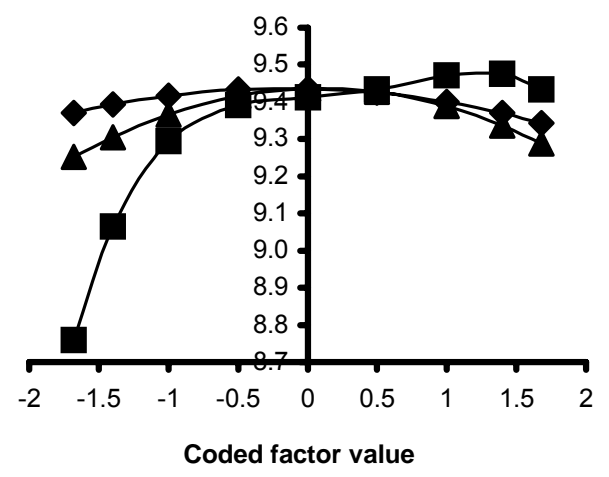

Figure 1: Partial-effects plot of $(\bullet)$ glucose, $(\boldsymbol{\bullet})$ yeast extract and $(\mathbf{\bullet}) \mathrm{pH}$

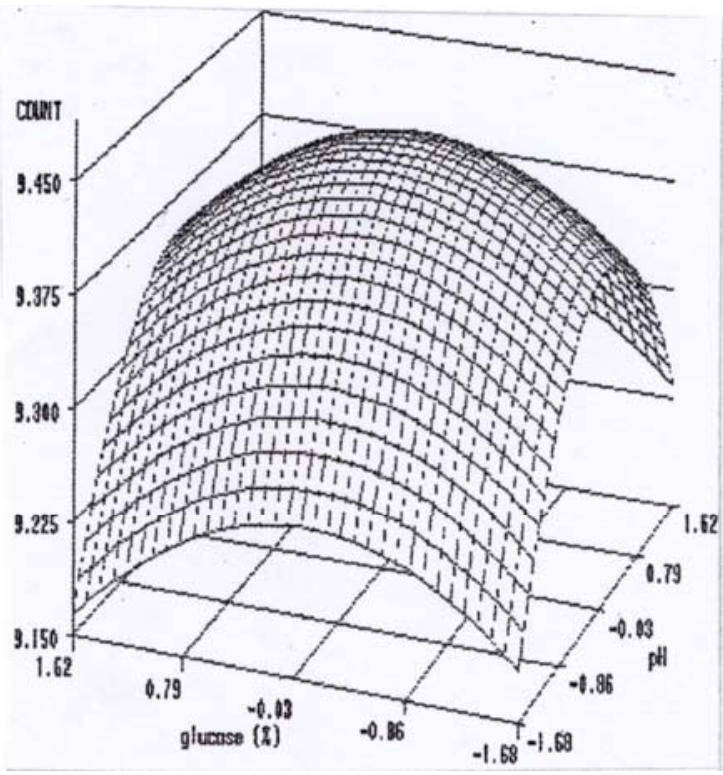

Figure 2: Response surface for the effects of glucose and yeast extract on the growth of $L$ salivarius i 24 at $\mathrm{pH}=6.10$

\section{Plotting Three Dimensional Response Surface Plots}

For any two of the three significant factors, a threedimensional response surface plot was drawn with the vertical axis representing $\log _{10} \mathrm{CFU} / \mathrm{mL}$ and two horizontal axes representing the coded levels of two explanatory factors. In each plot, the factors, which were not representing the two horizontal axes, were fixed at their optimum actual levels. All three plots were produced (Figures 2 to 4). In Figures 2 and 4 , it can be seen that the effects of pairs of factors were additive since there were no interactions. Additivity of the two factor effects means that the effect of one factor on the response is independent of the level of the other factor ( $\mathrm{Ha}$ et al., 2003; Liew, 2004).

Figure 3 shows non-additive effects of yeast extract and $\mathrm{pH}$ that were due to the significant interaction between them. The coefficient estimate of this interaction term had a negative sign $\left(b_{23}=-0.068625\right)$. By considering this interaction only, the negative sign may imply that for an increase of the response, the coded levels of yeast extract and $\mathrm{pH}$ must have the opposite sign-one greater than zero or one smaller than zero (Oh et al., 1995). However, the three-dimensional plot did not show this feature and at the optimum point, $X_{2}$ and $X_{3}=$ $(0.54,0.15)$. This is considered to be due to the other terms (linear, square, cubic and quartic terms) dominating the interaction term (Ha et al., 2003; Liew, 2004). 


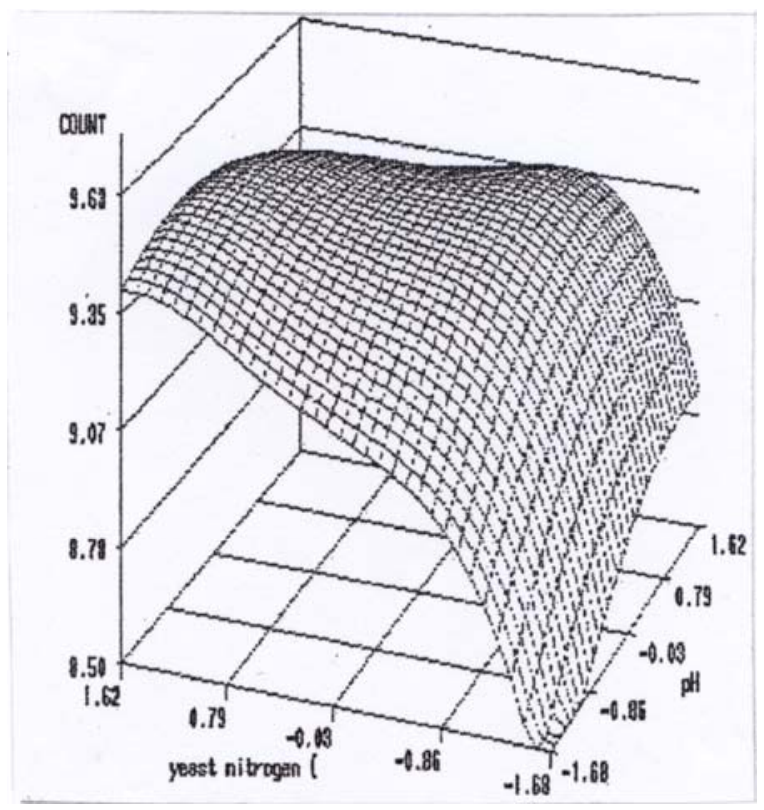

Figure 3: Response surface for the effects of yeast extract and $\mathrm{pH}$ on the growth of $L$ salivarius i 24 at glucose $=3.324 \%$

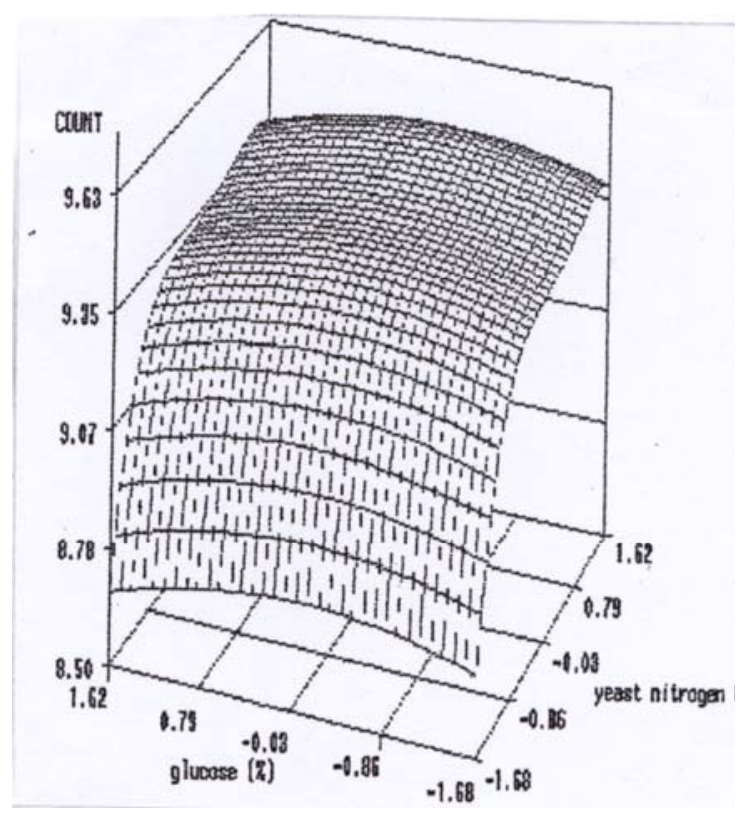

Figure 4: Response surface for the effects of glucose and $\mathrm{pH}$ on the growth of $L$ salivarius i 24 at yeast extract $=4.31 \%$

\section{Validation of the Optimum Points of the Factors}

An experiment was conducted to validate the optimum point of the factors found in this study. Here, we compared three growth media; the MRS medium, the optimum-point medium and the center-point medium. The compositions of these media are given in Table 6. Figure 5 shows three growth curves with the vertical axis representing $\log _{10} \mathrm{CFU} / \mathrm{mL}$ and the horizontal axis representing the fermentation time in hours.

The MRS medium produced the highest number of viable cells at $16 \mathrm{~h}$ (Figure 5). As for the optimum-point medium, even though the final cell concentration was less than that of the MRS medium, it took a shorter time to reach the highest number of viable cells, which was 8 h. This indicated that its productivity was higher compared to the MRS medium. The productivity can be estimated as final number of viable cells divided by the fermentation time. Centre-point medium also produced the highest number of viable cells at $8 \mathrm{~h}$, but the amount of viable cells was less than that of the optimum-point medium. Thus, the optimum-point medium seemed to be the most suitable among the three media in term of productivity of the cultivation process. It is also simpler in composition and might be cheaper than MRS medium.

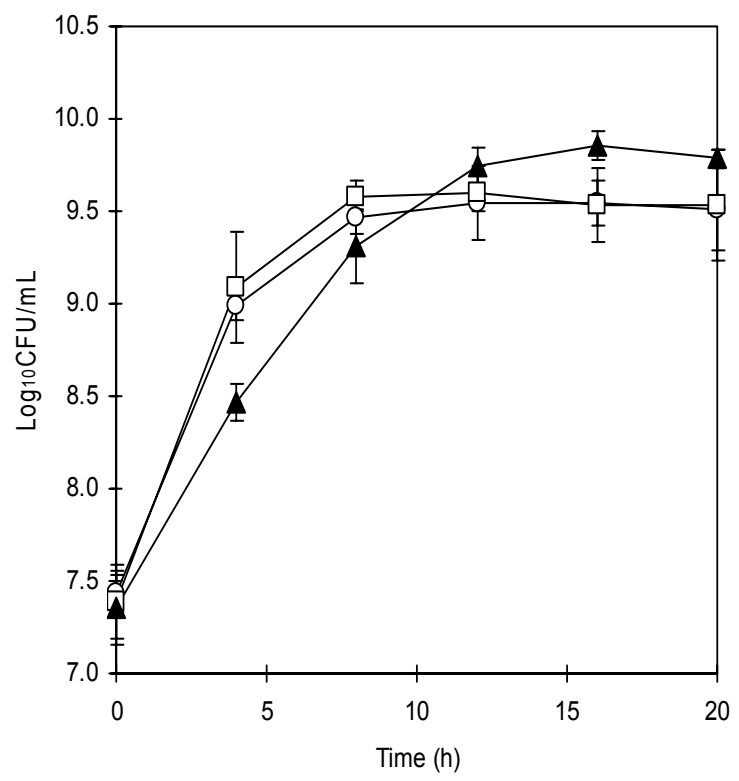

Figure 5: Growth curves of $L$ salivarius i 24 in MRS broth $(\boldsymbol{\Delta})$, optimum-point $(\square)$ and center point (o) media as obtained from the validation experiment 
Table 6: Compositions of three media for the growth of $L$ salivarius i 24

\begin{tabular}{|c|c|c|c|}
\hline \multirow[t]{2}{*}{ Composition } & \multicolumn{3}{|c|}{ Amount of component (\%) in } \\
\hline & $\begin{array}{l}\text { Optimum- } \\
\text { point }\end{array}$ & $\begin{array}{l}\text { Center- } \\
\text { point }\end{array}$ & MRS \\
\hline Glucose & 3.324 & 3.5 & 2.0 \\
\hline Yeast extract & 4.31 & 3.5 & 0.5 \\
\hline Tween 80 & 0.1 & 0.1 & 0.1 \\
\hline $\begin{array}{l}\text { Proteose } \\
\text { peptone }\end{array}$ & - & - & 1.0 \\
\hline Beef extract & - & - & 1.0 \\
\hline $\begin{array}{l}\text { Ammonium } \\
\text { citrate }\end{array}$ & - & - & 0.2 \\
\hline Sodium citrate & - & - & 0.5 \\
\hline $\begin{array}{l}\text { Magnesium } \\
\text { sulfate }\end{array}$ & 0.002 & 0.002 & 0.01 \\
\hline $\begin{array}{c}\text { Manganese } \\
\text { sulfate }\end{array}$ & - & - & 0.005 \\
\hline $\begin{array}{l}\text { Dipotassium } \\
\text { phosphate }\end{array}$ & 0.2 & 0.2 & 0.2 \\
\hline $\mathrm{pH}$ & 6.1 & 6 & 6.20 \\
\hline
\end{tabular}

\section{CONCLUSIONS}

This study demonstrated that RSM was used successfully in designing, analyzing, finding the optimum point and assessing the effects of factors leading to a higher growth rate of $L$. salivarius i 24 , which in turn, improve the overall productivity of the cultivation process. The optimum conditions of the factors for the growth of $L$. salivarius i 24 are as follows: glucose $=33.24 \mathrm{~g} / \mathrm{L}$, yeast extract $=43.1 \mathrm{~g} / \mathrm{L}$ and $\mathrm{pH}=6.1$. Even though the optimum levels of glucose and yeast extract were higher than the centre point level, the composition of the medium was less complicated than the commercial MRS medium. Hence, it could imply a reduction in the cost of production, which would translate to an economic gain. Another advantage of using the optimized medium is significant increase in the productivity as compared to for the MRS medium.

\section{REFERENCES}

Aeschlimann, A. and von Stockar, U. (1990). The effect of yeast extract supplementation on the production of lactic acid from whey permeate by Lactobacillus helveticus. Applied Microbiology and Biotechnology 32: 398 - 402.

Box, G.E.P. and Draper, N.R. (1982). Measures of lack of fit for response surface designs and predictor variable transformations. Technometrics 24: 1 - 8 .

Cordenunsi, B.R., Da Silva, R.S.F., Srivastava, K.C., Fabre-Sanches, S. and Perre, M.A. (1985). Mathematical model for the alcoholic fermentation in batch culture comparison between complete factorial (33) designs. Journal of Biotechnology 2: 1 - 12.
Gilliland, S.E. (1985). Concentrated starter cultures. In Bacterial starter cultures for foods, (Gilliland, S.E. Ed). pp 145-157. Florida: CRC Press Inc.

Ha, M.Y., Kim, S.W., Lee, Y.W., Kim, M.J. and Kim, S.J. (2003). Kinetics analysis of growth and lactic acid production in $\mathrm{pH}$-controlled batch cultures of Lactobacillus casei $\mathrm{KH}-1$ using yeast extract/ corn steep liquor/ glucose medium. Journal of Bioscience and Bioengineering 96: 134 - 140.

Jin, L.Z., Ho, Y.W., Abdullah, N. and Jalaludin, S. (1997). Probiotics in poultry: modes of action. World's Poultry Science Journal 53: 351 - 368.

Jin, L.Z., Ho, Y.W., Abdullah, N., Ali, A. M. and Jalaludin, S. (1996). Antagonistic effects of intestinal Lactobacillus isolates on pathogens of chickens. Letters in Applied Microbiology 23: 67-71.

Liew, S.L. (2004). Large-scale production of lactic acid bacteria for human probiotics. Ph.D Dissertation, Universiti Putra Malaysia, Malaysia.

Liew, S.L., Ariff, A.B., Raha, A.R. and Ho, Y.W. (2005). Optimization of medium composition for the production of a probiotic microorganism, Lactobacillus rhamnosus, using response surface methodology. International Journal of Food Microbiology 102: 137 - 142.

Lim, C.M. (2006). Optimization of fermentation and freeze-drying processes to enhance the productivity and stability of a probiotic, Lactobacillus salivarius I 24. Ph.D Dissertation, Universiti Putra Malaysia, Malaysia.

Logothetis, N and Wynn, H.P. (1989). Quality through design. New York: Oxford University Press.

Montgomery, C.D. (1991). Design and analysis of experiments. New York: John Wiley and Sons, Inc.

Oh, S.J., Rheem, S.S., Sim, J.H. and Kim, S.K. (1995). Optimization condition for the growth of Lactobaillus casei YIT 9018 in Typtone-Yeast Extract-Glucose medium by using response surface methodology. Applied and Environmental Microbiology 45: 3809 3814.

Rao, A.V., Jayaraman, K. and Lakshamanan, C.M. (1993). Production of lipase by Candida rugosa in solid state fermentation 2: media optimization and effect of aeration. Process Biochemistry 28: 391 395.

SAS Institute Inc. (1990a). SAS/STAT user's guide, release 6 04. SAS Institute Inc., Cary, N.C.

SAS-Institute Inc. (1990b). SAS/GRAPH user's guide, release 6.04. SAS Institute Inc., Cary, N.C.

Schepers, A.W., Thibault, J. and lacroix, C. (2002). Lactobacillus helveticus growth and lactic acid production during $\mathrm{pH}$-controlled batch cultures in whey permeate/yeast extract medium. Part I. Multiple factor kinetic analysis. Enzyme and Microbial Technology 30: 176 - 186.

Sen, R. (1997). Response surface optimization of the critical media components for the production of surfactin. Journal of Chemistry Technology and Biotechnology 68: $263-270$. 